\title{
Non-streptomycete actinomycetes nourish the current microbial antibiotic drug discovery
}

\author{
Polpass Arul Jose and Solomon Robinson David Jebakumar* \\ Department of Molecular Microbiology, School of Biotechnology, Madurai Kamaraj University, Madurai, India \\ *Correspondence: jsolomon_mrna@yahoo.com
}

Edited by:

Charles W. Knapp, University of Strathclyde, UK

Keywords: actinomycetes, rare actinomycetes, Streptomyces, non-streptomycetes, antibiotics

Antibiotic drug discovery is an indispensable process to combat aggressive ability of pathogenic microorganisms and emerging infectious diseases against health and well-being of people throughout the world. According to the updated and expanded data on natural products presented by Newman and Cragg (2012), the utility of natural products as sources of novel structures is still alive and the anti-infective area depends on natural products and their structures. The natural products with pharmaceutical importance are largely produced from primary and secondary metabolism of plants and microorganisms. Microbial natural products have made an incredible contribution to the antibiotic drug discovery and development process over last seven decades (Demain and Sanchez, 2009). Alexander Fleming's discovery of penicillin from a mold in 1928 and its subsequent progress into a medicine in the 1940s laid the foundation for development of microbial natural products as drugs (Fleming, 1929; Chain et al., 1940). Later, Waksman's report of actinomycin in 1940 and subsequent reports of streptothricin in 1942 and streptomycin in 1943 introduced the actinomycets as source of antibiotics (Waksman and Woodruff, 1940; Waksman, 1943; Comroe, 1978). In the end of 20th century, several actinobacterial natural products had found extensive applications in clinical field as antibacterial, antifungal, antiparasitic, and anticancer agents (Butler, 2004). Of all the reported bioactive compounds of microbial origin, $45 \%$ are produced by actinomycetes (Berdy, 2005). Moreover, $90 \%$ of practically used antibiotics are originated from the actinomycetes (Hamaki et al., 2005) and they are still being the chief natural antibiotic producers.

Since the report of streptomycin from the strains of Streptomyces griseus there has been a rapid escalation in antibiotic discovery from the genus Streptomyces (largest genus of Actinobacteria). Subsequently, members of this genus have become renowned as a prime source of natural antibiotics (Mohamed and Galal, 2005; Jose et al., 2011). It has been evidenced by continuing production of string of commercially important antibiotics like daptomycin, erythromycin, fosfomycin, lincomycin, neomycin, streptomycin, and tetracycline from industrially-important members of the genus Streptomyces (Mahajan and Balachandran, 2012). However, the likelihood of finding novel antimicrobial leads from these distinctive actinomycetes has recently dwindled upon the rediscovery of known compounds (Koehn and Carter, 2005) and the focus of current microbial drug discovery programs being reoriented toward other promising microbial resources. Other side of the coin, emergence of new infectious diseases and antibiotic resistance provoked in earlier infectious diseases has raised the need for novel antibiotics.

Against this backdrop, rare actinomycetes (non-streptomycetes) are currently isolated from diverse environments and intensively studied for potential leads for antibiotic discovery programs. The rare actinomycetes are usually regarded as strains of actinomycetes whose isolation frequency by conventional methods is much lesser than that of streptomycete strains (Seong et al., 2001). According to a recent review by Tiwari and Gupta (2012), this non-streptomycete actinomycetes group comprising diverse bioactive secondary metabolite producing members under following genera: Actinomadura, Actinoplanes, Amycolatopsis, Dactylosporangium, Kibdelosporangium, Kitasatospora, Microbiospora, Planomonospora, Planobispora, Salinispora, Streptosporangium, and Verrucosispora. The list has further been extended by recent reports of bioactive compounds from members of other rare genera, Nonomuraea (Beltrametti et al., 2003; Jose and Jebakumar, 2012; Flatt et al., 2013), Actinoalloteichus (Fu et al., 2011; Wang et al., 2013), Pseudonocardia (Oh et al., 2009; Barke et al., 2010; Carr et al., 2012), Saccharothrix (Murakami et al., 2009; Aouiche et al., 2012; Nakae et al., 2013), and Actinosynnema (Wei et al., 2010; Siyu-Mao et al., 2012). Moreover, basic knowledge of the habitats, physiology, and secondary metabolite diversity of the rare actinomycetes gradually increased (Tiwari and Gupta, 2012). Out of more than eight thousand antimicrobial products described in the ABL database, $16 \%$ produced by strains belong to rare genera of actinomycetes (Lazzarini et al., 2001).

Distribution of the rare actinomycetes has been found to be wide in terrestrial and aquatic environments (Tiwari and Gupta, 2012). Fair isolation methods have become indispensable as these rare actinomycetes exert slow growth while fast growing streptomycetes and fungal strains dominate in normal actinomycetes isolation methods. Different and isolation methods have to be employed for acquiring diverse actinomycetes from different sources. These methods employ variety of pretreatment techniques and enrichment techniques along with specific isolation medium amended with specific antimicrobial agents (Hayakawa, 2008). Tiwari and Gupta (2013) have reviewed almost 
all the selective isolation methods that have been developed to date for isolation of rare actinomycetes. In fact, all the isolation methods are designed to favor the growth of rare actinomycetes while suppressing the growth of undesired microorganisms.

In recent times, much attention has been given to isolate rare actinomycetes from diverse previously unexplored common as well as uncommon extreme environments. Numerous rare actinomycetes have been isolated from variety of soil samples (Seong et al., 2001; Gu et al., 2007; Li et al., 2007, 2010; Ara et al., 2013), plant materials (Qin et al., 2009; Janso and Carter, 2010; Zhao et al., 2011), marine sources (Zhang et al., 2006; Sun et al., 2010; Radhakrishnan et al., 2011; Goodfellow et al., 2012), extreme saline zones (Jose and Jebakumar, 2013), Volcanic zones (Lee and Lee, 2011) hyper arids (Okoro et al., 2009), glaciers (Reddy et al., 2010; Zhang et al., 2012), and much more. As a result, an array of rare actinomycetes available for current antimicrobial drug screening programs has increased. A comprehensive recent review by Tiwari and Gupta (2013) summarizes the reports of isolation rare actinomycetes from different natural habitats throughout the world. It is disclosed that, an unexpected variety of rare actinomycetes populates in diverse, previously unexplored natural habitates.

In conclusion, rare actinomycetes are being unveiled as highly prospective sources of bioactive compounds. Paths have already been sketched to reach these rare microorganisms but strides should be taken with specific isolation strategies. The progressing discoveries of novel bioactive compounds from these rare actinomycetes (non-streptomycetes) apparently opine that these organisms nourish the current antibiotic drug discovery programs.

\section{ACKNOWLEDGMENTS}

No specific funding was provided for this article. However, Polpass A. Jose was supported by Senior Research Fellowship from Council of Scientific and Industrial Research, India.

\section{REFERENCES}

Aouiche, A., Sabaou, N., Meklat, A., Zitouni, A., Bijani, C., Mathieu, F., et al. (2012). Saccharothrix sp. PAL54, a new chloramphenicol-producing strain isolated from a Saharan soil. World J. Microbiol. Biotechnol. 28, 943-951. doi: 10.1007/s11274-011-0892-2

Ara, I., Bakir, M. A., Hozzein, W. N., and Kudo, T. (2013). Population morphological and chemotaxonomical characterization of diverse rare actinomycetesin the mangrove and medicinal plant rhizosphere. Afr. J. Microbiol. Res. 7, 1480-1488. doi: 10.5897/AJMR12.452

Barke, J., Seipke, R. F., Grüschow, S., Heavens, D., Drou, N., Bibb, M. J., et al. (2010). A mixed community of actinomycetes produce multiple antibiotics for the fungus farming ant Acromyrmex octospinosus. BMC Biol. 8:109. doi: 10.1186/17417007-8-109

Beltrametti, F., Lazzarini, A., Brunati, C., Marazzi, A., Jovetic, S., Selva, E., et al. (2003). Production and characterization of monochlorinated and dechlorinated A40926 derivatives. J. Antibiot. 56, 773-782. doi: 10.7164/antibiotics.56.773

Berdy, J. (2005). Bioactive microbial metabolites. J. Antibiot. 58, 1-26. doi: 10.1038/ja.2005.1

Butler, M. S. (2004). The role of natural product chemistry in drug discovery. J. Nat. Prod. 67, 2141-2215. doi: 10.1021/np040106y

Carr, G., Derbyshire, E. R., Caldera, E., Currie, C. R., and Clardy, J. (2012). Antibiotic and antimalarial quinones from fungus-growing ant-associated Pseudonocardia sp. J. Nat. Prod. 75, 1806-1809. doi: 10.1021/np300380t

Chain, E., Florey, H. W., Gardner, A. D., Heatley, N. G., Jennings, M. A., Orr-Ewing, J., et al. (1940). Penicillin as a chemotherapeutic agent. Lancet 2, 226-228.

Comroe, J. H. Jr. (1978). Pay dirt: the story of streptomycin. I: from Waksman to Waksman. Retrospectroscope. Am. Rev. Respir. Dis.117, 773-781.

Demain, A. L., and Sanchez, S. (2009). Microbial drug discovery: 80 years of progress. J. Antibiot. 62, 5-16. doi: 10.1038/ja.2008.16

Flatt, P. M., Wu, X., Perry, S., and Mahmud, T. (2013). Genetic insights into pyralomicin biosynthesis in Nonomuraea spiralis IMC A-0156. J. Nat. Prod. 76, 939-946. doi: 10.1021/np400159a

Fleming, A. (1929). On the antibacterial action of cultures of Penicillium, with special reference to their use in the isolation of $B$. influenzae. Br. J. Exp. Pathol. 10, 226-236.

Fu, P., Liu, P., Li, X., Wang, Y., Wang, S., Hong, K., et al. (2011). Cyclic bipyridine glycosides from the marine-derived actinomycete Actinoalloteichus cyanogriseus WH1-2216-2216. Org. Lett. 13, 5948-5951. doi: 10.1021/ol202245s

Goodfellow, M., Stach, J. E., Brown, R., Bonda, A. N., Jones, A. L., Mexson, J., et al. (2012). Verrucosispora maris sp. nov., a novel deepsea actinomycete isolated from a marine sediment which produces abyssomicins. Antonie Van Leeuwenhoek 101, 185-193. doi: 10.1007/s10482011-9651-5

Gu, Q., Paœciak, M., Luo, H., Gamian, A., Liu, Z., and Huang, Y. (2007). Ruania albidiflava gen. nov., sp. nov., a novel member of the suborder Micrococcineae. Int. J. Syst. Evol. Microbiol. 57, 809-814. doi: 10.1099/ijs.0.64635-0

Hamaki, T., Suzuki, M., Fudou, R., Jojima, Y., Kajiura, T., Tabuchi, A., et al. (2005). Isolation of novel bacteria and actinomycetes using soil-extract agar medium. J. Biosci. Bioeng. 99, 485-492. doi: 10.1263/jbb. 99.485

Hayakawa, H. (2008). Studies on the isolation and distribution of rare actinomycetes in soil. Actinomycetologica 22, 12-19. doi: 10.3209/saj.SAJ220103

Janso, J. E., and Carter, G. T. (2010). Biosynthetic potential of phylogenetically unique endophytic actinomycetes from tropical plants. Appl. Environ. Microbiol. 76, 4377-4386. doi: 10.1128/AEM.02959-09

Jose, P. A., and Jebakumar, S. R. D. (2012). Phylogenetic diversity of actinomycetes cultured from coastal multipond solar saltern in Tuticorin, India. Aquat. Biosyst. 8, 23. doi: 10.1186/20469063-8-23

Jose, P. A., and Jebakumar, S. R. D. (2013). Phylogenetic appraisal of antagonistic, slow growing actinomycetes isolated from hypersaline inland solar salterns at Sambhar salt Lake, India. Front. Microbiol. 4:190. doi: 10.3389/fmicb.2013. 00190

Jose, P. A., Santhi, V. S., and Jebakumar, S. R. D. (2011). Phylogenetic-affiliation, antimicrobial potential and PKS gene sequence analysis of moderately halophilic Streptomyces sp. inhabiting an Indian saltpan. J. Basic Microbiol. 51, 348-356. doi: 10.1002/jobm.201000253

Koehn, F. E., and Carter, G. T. (2005). The evolving role of natural products in drug discovery. Nat. Rev. Drug Discov. 4, 206-220. doi: $10.1038 / \operatorname{nrd} 1657$

Lazzarini, A., Cavaletti, L., Toppo, G., and Marinelli, F. (2001). Rare genera of actinomycetes as potential producers of new antibiotics. Antonie Van Leeuwenhoek 79, 399-405.

Lee, D. W., and Lee, S. D. (2011). Allocatelliglobosispora scoriae gen. nov., sp. nov., isolated from volcanic ash. Int. J. Syst. Evol. Microbiol. 61, 264-270.

Li, J., Zhao, G.-Z., Huang, H.-Y., Zhu, W.-Y., Lee, J.-C., Kim, C.-J., et al. (2010). Pseudonocardia rhizophila sp. nov., a novel actinomycete isolated from a rhizosphere soil. Antonie van Leeuwenhoek 98, 77-83. doi: 10.1007/s10482-010-9431-7

Li, W.-J., Xu, P., Schumann, P., Zhang, Y.-Q., Pukall, R., Xu, L.-H., et al. (2007). Georgenia ruanii sp. nov., a novel actinobacterium isolated from forest soil in Yunnan (China), and emended description of the genus Georgenia. Int. J. Syst. Evol. Microbiol. 57, 1424-1428. doi: 10.1099/ijs.0.64749-0

Mahajan, G. B., and Balachandran, L. (2012). Antibacterial agents from Actinomycetes - a review. Front. Biosci. E4, 240-253.

Mohamed, S. H., and Galal, A. M. (2005). Identification and antiviral activities of some halotolerant Streptomycetes isolated from Qaroon Lake. Int. J. Agr. Biol. 5, 747-753.

Murakami, R., Shinozaki, J., Kajiura, T., Kozone, I., Takagi, M., Shin-Ya, K., et al. (2009). Ammocidins, B, C and D, new cytotoxic 20-membered macrolides from Saccharothrix sp. AJ9571. J. Antibiot. 62, 123-127. doi: 10.1038/ja.2008.23

Nakae, K., Kurata, I., Kojima, F., Igarashi, M., Hatano, M., Sawa, R., et al. (2013). Sacchathridine, A, a prostaglandin release inhibitor from Saccharothrix sp. J. Nat. Prod. 76, 720-722. doi: $10.1021 / \mathrm{np} 3006327$ 
Newman, D. J., and Cragg, G. M. (2012). Natural products as sources of new drugs over the 30 years from 1981 to 2010. J. Nat. Prod. 75, 311-335. doi: $10.1021 / \mathrm{np} 200906 \mathrm{~s}$

Oh, D. C., Poulsen, M., Currie, C. R., and Clardy, J. (2009). Dentigerumycin: a bacterial mediator of an ant-fungus symbiosis. Nat. Chem. Biol. 5, 391-393.

Okoro, C. K., Brown, R., Jones, A. L., Andrews, B. A., Asenjo, J. A., Goodfellow, M., et al. (2009). Diversity of culturable actinomycetes in hyper-arid soils of the Atacama Desert, Chile. Antonie Van Leeuwenhoek 95, 121-133. doi: 10.1007/s10482008-9295-2

Qin, S., Li, J., Chen, H.-H., Zhao, G.-Z., Zhu, W.Y., Jiang, C.-L., et al. (2009). Isolation, diversity, and antimicrobial activity of rare actinobacteria from medicinal plants of tropical rain forests in Xishuangbanna, China. Appl. Environ. Microbiol. 75, 6176-6186. doi: 10.1128/AEM.01034-09

Radhakrishnan, M., Balagurunathan, R., Selvakumar, N., Doble, M., and Kumar, V. (2011). Bioprospecting of marine derived actinomycetes with special reference to antimycobacterial activity Indian. J. Geo Marine Sci. 40, 407-410.

Reddy, G. S. N., Pradhan, S., Manorama, R., and Shivaji, S. (2010). Cryobacterium roopkundense sp. nov., a psychrophilic bacterium isolated from glacial soil. Int. J. Syst. Evol. Microbiol. 60, 866-870.

Seong, C. N., Choi, J. H., and Baikm, K.-S. (2001). An improved selective isolation of rare actinomycetes from forest soil. J. Microbiol. 39, 17-23.

Siyu-Mao, Hong-Chen, Li-Chen, ChuanxiWang, Wei-Jia, Xiaoming-Chen, et al.
(2012). Two novel ansamitocin analogs from Actinosynnema pretiosum. Nat. Prod. Res. doi: 10.1080/14786419.2012.733388. [Epub ahead of print].

Sun, W., Dai, S., Jiang, S., Wang, G., Liu, G., Wu, H., et al. (2010). Culture-dependent and culture-independent diversity of actinobacteria associated with the marine sponge Hymeniacidon perleve from the South China Sea. Antonie Van Leeuwenhoek 98, 65-75. doi: 10.1007/s10482-0109430-8

Tiwari, K., and Gupta, R. K. (2012). Rare actinomycetes: a potential storehouse for novel antibiotics. Crit. Rev. Biotechnol. 32, 108-132. doi: $10.3109 / 07388551.2011 .562482$

Tiwari, K., and Gupta, R. K. (2013). Diversity and isolation of rare actinomycetes: an overview. Crit. Rev. Biotechnol. 39, 256-294.

Waksman, S. A. (1943). Production and activity of streptothricin. J. Bacteriol. 46, 299-310.

Waksman, S. A., and Woodruff, H. B. (1940) Bacteriostatic and bacteriocidal substances produced by soil actinomycetes. Proc. Soc. Exp. Biol. 45, 609-614. doi: 10.3181/00379727-45-11768

Wang, X. J., Zhang, J., Wang, J. D., Qian, P. T., Liu, C. X., and Xiang, W. S. (2013). Novel cyclopentenone derivatives produced by a rare actinobacterial strain Actinoalloteichus nanshanensis sp. nov. NEAU 119. Nat. Prod. Res. doi: $\quad 10.1080 / 14786419.2013 .771349$. (in press).

Wei, G. Z., Bai, L. Q., Yang, T., Ma, J., Zeng, Y., Shen, Y. M., et al. (2010). A new antitumour ansamitocin from Actinosynnema pretiosum. Nat. Prod. Res. 24, 1146-1150. doi: 10.1080/14786410902916552
Zhang, D. C., Schumann, P., Redzic, M., Zhou, Y. G., Liu, H. C., Schinner, F., et al. (2012). Alpinus sp. nov., a psychrophilic actinomycete isolated from alpine glacier cryoconite. Int. J. Syst. Evol. Microbiol. 62, 445-450. doi: 10.1099/ijs.0.031047-0

Zhang, H., Lee, Y. K., Zhang, W., and Lee, H. K. (2006). Culturable actinobacteria from the marine sponge Hymeniacidon perleve: isolation and phylogenetic diversity by $16 \mathrm{~S}$ rRNA gene-RFLP analysis. Antonie Van Leeuwenhoek 90, 159-169.

Zhao, G.-Z., Li, J., Huang, H.-Y., Zhu, W.-Y., Zhao, L.-X., Tang, S.-K., et al. (2011). Pseudonocardia artemisiae sp. nov., isolated from surface-sterilized Artemisia annua L. Int. J. Syst. Evol. Microbiol. 61, 1061-1065.

Received: 09 July 2013; accepted: 31 July 2013; published online: 20 August 2013.

Citation: Jose PA and Jebakumar SRD (2013) Nonstreptomycete actinomycetes nourish the current microbial antibiotic drug discovery. Front. Microbiol. 4:240. doi: 10.3389/fmicb.2013.00240

This article was submitted to Antimicrobials, Resistance and Chemotherapy, a section of the journal Frontiers in Microbiology.

Copyright (c) 2013 Jose and Jebakumar. This is an open-access article distributed under the terms of the Creative Commons Attribution License (CC BY). The use, distribution or reproduction in other forums is permitted, provided the original author(s) or licensor are credited and that the original publication in this journal is cited, in accordance with accepted academic practice. No use, distribution or reproduction is permitted which does not comply with these terms. 